\title{
Poder e anarquismo: refletindo com Habermas
}

\author{
Power and Anarchism: \\ reflecting with Habermas
}

Claudio Ricardo Martins dos Reis

Doutorando em Filosofia na UFRGS Bolsista CAPES

Resumo: Meu objetivo é analisar a concepção anarquista de poder, trazendo para o debate Jürgen Habermas e sua crítica à Hannah Arendt. Começo apresentando uma breve análise conceitual do poder. Em seguida exponho a concepção de poder nos anarquistas clássicos. Depois, apresento objeções de Habermas ao projeto anarquista e à concepção de poder (e de política) em Arendt. Passo, então, a avaliar se aquelas objeções de Habermas endereçadas diretamente ao anarquismo são motivadas e se as objeções que ele direciona à Arendt podem se transferir ao projeto anarquista. Para tal avaliação, utilizo as categorias de Habermas tanto para reanalisar o projeto dos anarquistas clássicos quanto para analisar a concepção de poder numa vertente atual do anarquismo organizado. Concluo que aquelas objeções de Habermas ao anarquismo carecem de justificação e que a perspectiva anarquista possui pontos em comum tanto com Arendt quanto com Habermas, devido à ampla valorização do agir comunicativo e por não excluir o papel da ação estratégica.

Palavras-chave: Ação Comunicativa; Ação Estratégica; Dominação; Federalismo; Poder Popular. 
Abstract: The aim of this work is to analyze the anarchist conception of power, arguing with Jürgen Habermas. I begin by introducing a brief conceptual analysis of power. Then I set out how the classical anarchists reflect upon the conception of power. In the third place, I present Habermas's objections to the anarchist project and to the conception of power (and politics) in Arendt. Following, I assess whether Habermas's objections to anarchism are motivated and whether the objections he addresses to Arendt can be applied to the anarchist project. For this evaluation, I use the categories of Habermas both to reanalyze the project of the classical anarchists and to analyze how the conception of power currently survives in a form of organized anarchism. I conclude that Habermas's objections to anarchism have no justification and that the anarchist perspective shares conceptual elements with both Arendt and Habermas, because of the widespread appreciation of communicative action and by not excluding the role of strategic action.

Keywords: Communicative Action; Strategic Action; Domination; Federalism; Popular Power.

$\mathbf{N}$ a linguagem comum, o termo "poder" costuma ter um sentido mais negativo do que neutro ou positivo. Certamente, todos já ouvimos críticas ao "poder". No entanto, poderíamos perguntar: o que é o poder? A pergunta por "o que é [...]?", contudo, pede uma definição que deveria valer independente dos usos e objetivos que se tem em mente. Mesmo que criássemos esse tipo de definição, em que ela nos ajudaria? A pergunta que buscamos é de um tipo diferente. Deveríamos perguntar: o que queremos dizer com os predicados "poderoso" ou "impotente"? Que sentido(s) esses predicados possuem em nossa prática linguística? Que relações eles possuem com o que denominamos "ação", "comunicação", "imposição", "dominação", etc.? A que tipo de "coisas" (pessoas, instituições, classes sociais, relações entre pessoas, relações entre instituições, etc.) atribuímos aqueles predicados?

Como exemplo, podemos pensar em três expressões do poder em que a crítica toma forma. Costuma-se criticar: (1) todo poder, isto é, qualquer forma em que o poder se expressa; (2) o 
poder enquanto dominação; (3) o poder das classes dominantes. Para que essas três críticas possam ser bem compreendidas, deve-se esclarecer o conceito de poder (pressuposto em cada uma delas), além dos conceitos de dominação (pressuposto em 2) e de classes dominantes (pressuposto em 3). Apresentarei um breve esclarecimento desses conceitos no próximo tópico, abordando o modo como foram utilizados por uma perspectiva em particular, aquela dos anarquistas clássicos, cuja produção de ideias se deu na segunda metade do século XIX até as primeiras décadas do século XX.

Meu principal objetivo neste trabalho é analisar a concepção de poder no anarquismo. Após analisá-la nos anarquistas clássicos, apresento uma objeção do filósofo e sociólogo alemão Jürgen Habermas ao projeto anarquista. Essa objeção envolve a ideia de que o anarquismo é uma utopia (no sentido pejorativo do termo) que, apesar de seus potenciais democráticos, fracassa diante das necessidades da sociedade moderna.

Minha interpretação é que essa crítica se fundamenta numa tese substancial a respeito do anarquismo, segundo a qual o anarquismo é contra toda e qualquer institucionalização. De fato, no mesmo texto em que Habermas apresenta essa crítica, ele utiliza o termo "anti-institucionalismo" em sua breve descrição do projeto anarquista. Isso permite a Habermas conceber o anarquismo como um modelo utópico em contraposição a um modelo de crítica imanente.

Habermas desenvolve uma crítica similar à concepção de poder e de política em Hannah Arendt, de cuja concepção ele também interpreta como um modelo utópico. Eu apresento, então, brevemente a crítica de Habermas à Arendt com o objetivo de avaliar se essa crítica pode se transferir ao projeto anarquista. Minhas conclusões - baseadas na análise dos anarquistas clássicos, no destaque à noção de federalismo e na menção a experiências históricas com protagonismo, participação e influência anarquista - é de que a objeção de Habermas ao anarquismo é desmotivada e que sua objeção à Arendt não se transfere ao projeto anarquista. Ao final, analiso a concepção de poder de uma vertente atual do anarquismo organizado, o que desponta como mais uma evidência contra a objeção de Habermas. 


\section{Clássicos anarquistas: o poder como dominação exercida por classes dominantes}

Mikhail Bakunin (1814 - 1876), Piotr Kropotkin (1842 - 1921) e Errico Malatesta (1853 - 1932) estão entre os principais teóricos do anarquismo clássico. O poder, em suas concepções, tinha um sentido expressamente negativo ${ }^{6}$. Podemos afirmar que os anarquistas do século XIX e início do século XX entendiam o poder como sinônimo de dominação. Quando se diziam contra o poder, isso significava que eram contra a dominação. E eles entendiam a dominação como imposição coercitiva da vontade (o que dava a essa categoria um sentido mais amplo que o de exploração, associada ao trabalho especificamente). Essa imposição coercitiva era vista como a expressão de uma sociedade dividida em classes. Portanto, os anarquistas clássicos concebiam o poder como imposição coercitiva exercida por classes dominantes. Por lutarem contra o poder, assim entendido, são chamados libertários ${ }^{7}$ (ou antiautoritários), o que faz deles também, necessariamente, anticapitalistas.

$6 \quad$ Por exemplo, para Bakunin, "o mal está na busca do poder, no amor pelo governo, na sede da autoridade" (Bakunin, 2016a, p. 300, grifo meu) e "quem fala de poder político, fala de dominação" (Bakunin, 1998, p. 100, grifo meu); para Kropotkin, "o Estado, tendo sido a força à qual as minorias recorreram para estabelecer e organizar seu poder sobre as massas, não pode ser a força que servirá para destruir esses privilégios." (Kropotkin, 1912, p. 68, tradução e grifo meus); para Malatesta, "revolução significa, no sentido histórico da palavra, reforma radical das instituições, conquistada rapidamente mediante a insurreição violenta do povo contra o poder e os privilégios constituídos" (Malatesta, 2007, p. 82, tradução e grifo meus).

7 Não me refiro ao "libertarianismo", mas ao campo socialista libertário. Apesar de o ultraliberalismo de direita se reivindicar "libertário", esse termo nasceu no interior da esquerda. O primeiro registro de alguém que utilizou o termo libertário para si num sentido político é de uma carta de 1857, escrita pelo anarquista francês Joseph Dejácque. Nessa carta, Dejácque critica Proudhon por suas visões sexistas sobre a mulher e sua defesa da propriedade individual do produto do trabalho e da economia de mercado. Em 1858, Dejácque passa a editar, em Nova York, o periódico Le Libertaire: Journal du Mouvement Social, o primeiro jornal anarco-comunista publicado nas Américas. Posteriormente, em 1880, o termo "comunismo libertário" é utilizado no Congresso Anarquista Regional Francês em Le Havre. "Libertário" continuou a ser um termo utilizado nas décadas seguintes e até hoje entre os anarquistas, concebido quase como sinônimo de anarquismo. Alguns pesquisadores e militantes, no entanto, optam por uma distinção entre libertários 
Assim como outros anarquistas, Malatesta entende que "socialismo e anarquia são termos que não são nem opostos nem equivalentes, mas estreitamente ligados um ao outro" (Malatesta, 2014 [1896], p. 50, grifos do autor). A seu ver, os ideais anarquistas só poderiam se efetivar numa sociedade socialista, e os ideais socialistas, numa sociedade anárquica. Haveria, portanto, uma relação de reforço mútuo entre socialismo e anarquia. Se um tende a se afastar do outro, é porque seus ideais foram desvirtuados.

Essa interpretação é realizada pelos anarquistas a partir da sua noção de classes dominantes, que inclui tanto aqueles que detêm os meios de produção quanto aqueles que detêm os meios de ação (política). Portanto, o poder das classes dominantes não se limita à classe capitalista e sua presença no Estado com vistas a garantir seus interesses. A interpretação anarquista concebe a própria burocracia como classe dominante.

Nesse sentido, a crítica atinge a burguesia, mas também a classe governamental, burocrática. Por isso os anarquistas consideram o socialismo estatal (burocrático) como outra forma de dominação. Se inflamos o "corpo sacerdotal do Estado", como se referia Bakunin à cascata de hierarquias que constitui o Estado, inflamos a concentração de poder, na medida em que outras atividades passariam a ser absorvidas pelo Estado. No entanto, para entender a posição de Bakunin, não devemos interpretar essa afirmação pela perspectiva do liberalismo econômico. Enquanto, a partir dessa mesma afirmação, a doutrina liberal concluiria pela limitação do Estado e pelo avanço de uma economia de mercado sem qualquer questionamento para a relação capital/trabalho, Bakunin conclui pela abolição do Estado e da propriedade privada enquanto órgãos da classe dominante. A intenção de Bakunin não é enfraquecer o Estado para fortalecer o capital contra o trabalho, mas destacar que os e anarquistas, considerando que nem todo libertário é anarquista mas todo anarquista é libertário (ainda assim, os "libertarianos" de direita não são libertários nessa concepção). Muitos movimentos são organizados com base em práticas libertárias mesmo que não tenham interesse no (ou não conheçam o) campo teórico do anarquismo. Os anarquistas, além de defenderem práticas libertárias, enxergam-se como fazendo parte da vertente histórica e teórica do anarquismo. 
trabalhadores só podem ser livres se emancipados do Estado e do capital, rechaçando, portanto, não só a posição liberal, mas também a posição marxista ortodoxa que concebe como meio a criação de um estado todo-poderoso. Para Bakunin, os meios devem prefigurar os fins e precisam ser identificados nos órgãos da classe trabalhadora.

Mencionei que a concepção de poder dos clássicos anarquistas é de poder como dominação. Essa dominação seria exercida por classes dominantes, compostas prioritariamente pela burguesia (detentora de poder por controlar os meios de produção) e pela burocracia (detentora de poder por controlar os meios de ação política) ${ }^{8}$. Isso, contudo, não implica que a burguesia e a burocracia sejam classes sem relações estreitas. De fato, a compreensão dos anarquistas é de que a burguesia molda a burocracia para seus próprios fins, beneficiando-se dela. Nesse sentido, para efetivamente se compreender o poder da classe capitalista, dever-se-ia compreender também seu poder sobre a burocracia.

Ainda assim, no entanto, os anarquistas entendem que se os meios de produção passam à gestão e controle do Estado, a dominação continua, na medida em que a burocracia não depende da burguesia para atuar como classe dominante. O proprietário dos meios de produção deixa de ser o burguês, mas passa a ser o Estado. Aos olhos dos anarquistas, esse fenômeno não corresponde à socialização dos meios de produção, em seu sentido genuíno, mas tão somente à estatização desses meios. Sua concepção é a de que se os meios de produção são geridos e controlados pelo Estado, não o são pelos trabalhadores; inversamente, se são geridos e controlados pelos trabalhadores, não o são pelo Estado. A alternativa visualizada pelos anarquistas é a gestão direta pelos trabalhadores em seus próprios locais de trabalho, não como uma suposta etapa posterior a um estado todo-poderoso, mas como resultado de um fortalecimento dos órgãos de classe, levando às últimas consequências a ideia de que "a emancipação dos trabalhadores é obra dos próprios trabalhadores", não de uma elite pretensamente popular agindo em seu nome.

8 Também o clero, com sua estrutura hierárquica e suas pretensões conservadoras, era visto como classe dominante pelos anarquistas clássicos. 
A partir desse quadro interpretativo, que busquei simplificar ao máximo, podemos notar que os anarquistas clássicos tinham uma compreensão da vita activa em que a ação ocupava um lugar fundamental ${ }^{9}$. Sua crítica contundente dos métodos burocráticos, inclusive quando atuam no interior de movimentos populares (como os métodos que resultaram na expulsão de Bakunin, Guillaume e outros da Associação Internacional dos Trabalhadores, A.I.T.) deve-se à compreensão de que esses métodos operam no sentido oposto à ação genuína, que pressupõe um ambiente com condições de igualdade. Esse mesmo quadro interpretativo, que não descuida o valor da ação, movia os anarquistas a defender a organização federalista da A.I.T., em contraposição às propostas centralistas (ver Malon, 2014).

\section{Objeção de Habermas ao anarquismo}

Habermas (2001) possui uma teoria social dualista da modernização das sociedades, que lhe permite incorporar, distinguir e contrapor mundo da vida e sistema. Ele diagnostica um processo de desacoplamento entre essas duas esferas sociais. $\mathrm{O}$ mundo da vida estaria ligado à reprodução simbólica da sociedade, que ocorre prioritariamente por ações comunicativas. $\mathrm{O}$ sistema estaria vinculado à reprodução material da sociedade, que ocorre predominantemente por meio de ações instrumentais funcionalmente coordenadas. As sociedades modernas, portanto, são dualistas na visão de Habermas. Não podemos entendê-las adequadamente reduzindo-as aos componentes do mundo da vida nem as reduzindo aos componentes do sistema.

Podemos defender a tese de que os anarquistas clássicos, mencionados acima, eram contrários à colonização do mundo da vida pelo sistema (tal como o próprio Habermas). Mas uma tese, mais substancial, poderia ser a de que eles eram

$9 \quad$ Vita activa é um termo central em Hannah Arendt (2010 [1958]), sendo constituída pelas categorias de trabalho, obra e ação. Arendt considera que Karl Marx destacou a importância do trabalho e da obra, mas que não deu o devido valor à categoria de ação. Ela busca recuperar o valor da ação, perdido na filosofia e sociedade modernas. Meu ponto é chamar a atenção de que essa objeção de Arendt a Marx não se aplicaria aos anarquistas, mesmo àqueles da época de Marx. 
contrários a toda e qualquer institucionalização. Entendo que é com base nessa última tese que Habermas interpreta a posição anarquista em Soberania popular como procedimento (Habermas, 1990). Por isso, apesar de reconhecer um grande potencial democrático no anarquismo, Habermas afirma:

\begin{abstract}
Esse projeto anarquista de uma sociedade que desponta no entrelaçamento horizontal de associações permaneceu sempre utópico; apenas hoje é que ele fracassa diante da necessidade de direcionamento e organização das sociedades modernas (Habermas, 1990, p. 107, grifos meus).
\end{abstract}

Em outras palavras, o projeto anarquista estaria "datado". A complexidade das sociedades atuais faria desse projeto, que antes não passou de uma utopia, hoje uma impossibilidade. De fato, essa crítica é bastante comum entre marxistas ${ }^{10}$. No entanto, ela não sobrevive a uma análise histórica minimamente adequada. O anarquismo foi protagonista nas revoluções ocorridas no México em 1910 (Samis, 2003; Trejo, 2005; Zarcone, 2006), na Ucrânia em 1917 e 1919 (Arshinov, 1976; Volin, 1977; Schujman, 2000; Shubin, 2010), na Manchúria em 1929 (Crisi, 2015) e na Espanha em 1936 (Guérin, 1968; Le Libertaire \& Le Monde Libertaire, 2002; Leval, Berthier \& Mintz, 2002). O sindicalismo revolucionário e o anarco-sindicalismo, que são parte da "ampla tradição anarquista", foram estratégias hegemônicas nos movimentos de trabalhadores do início do século XX em diversos países, como Argentina, Brasil, Chile, Cuba, França, Países Baixos, Peru, Portugal e Uruguai (Schmidt \& Van der Walt, 2009). Entre as experiências mais recentes, profundamente compatíveis com o projeto anarquista, estão desde os cordões industriais no Chile em 1972 e 1973, até as comunidades rurais zapatistas no México, de 1994 até hoje. Como afirmam Schmidt e Van der Walt:

\footnotetext{
$10 \quad$ Em seu livro Revolucionários, Eric Hobsbawm (1985, p. 91-92) apresenta posição semelhante quando afirma, por exemplo, que foi a "monumental ineficiência do anarquismo que, para a maioria das pessoas da minha geração [...], determinou a nossa rejeição a ele" e que "nenhuma dose de simpatia pode alterar o fato de que ele [o anarquismo], como movimento revolucionário, tenha sido ideado quase para o fracasso". Os Revolucionários Ineficazes de Hobsbawm (Silva, 2015) apresenta uma crítica contundente à interpretação de Hobsbawm do anarquismo.
} 
Muitos dos ideais e das práticas associadas à ampla tradição anarquista - ação direta, democracia participativa, a posição de que os meios devem ser combinados com os fins, solidariedade, o respeito pelo indivíduo, a rejeição da manipulação, a ênfase na importância da liberdade de opinião e da diversidade, a oposição à opressão de raça, nacionalidade e gênero - são precisamente aqueles reivindicados por milhões de pessoas no período pós-soviético. (Schmidt \& Van der Walt, 2009, p. 25)

De fato, como Sam Dolgoff expressa em seu texto The Relevance of Anarchism to Modern Society:

A crescente complexidade da sociedade está tornando o anarquismo mais e não menos relevante para a vida moderna. É precisamente essa complexidade e diversidade, sobretudo com a preocupação primordial pela liberdade e pelos valores humanos, que levaram os pensadores anarquistas a basear suas ideias nos princípios da difusão do poder, da autogestão e do federalismo. (Dolgoff, 1977, p. 11, grifos do autor)

A meu ver, a objeção de Habermas decorre de sua interpretação do anarquismo a partir da tese antes referida como substancial, segundo a qual o anarquismo seria contra toda e qualquer institucionalização. De fato, Habermas utiliza o termo "anti-institucionalismo" ao apresentar uma breve descrição do projeto anarquista (Habermas, 1990, p. 106). No entanto, essa tese não se sustenta. Ela se contrapõe à principal proposta organizativa dos anarquistas: o federalismo libertário.

Em seu livro Do Federalismo (Berthier, 2011), René Berthier apresenta a forma política alternativa defendida pelos anarquistas. Um trecho bastante conciso e elucidativo poderá ajudar nesta discussão:

O federalismo é um modo de organização no qual cada instância constitutiva do organograma é autônoma, no que diz respeito às questões que a concernem diariamente, e que delega, por intermédio de um ou vários representantes designados, uma parcela de sua soberania nas instâncias superiores do organograma para as questões que ultrapassam seu próprio campo de intervenção. Não há, portanto, nem captação de todo o poder pelo cume (centralismo), nem atomização do poder (autonomismo). (Berthier, 2011, p. 31-32)

A concepção federalista teve origem na classe operária francesa - desenvolvendo-se na Primeira Internacional (1864- 
1877) e na Comuna de Paris (1871) - e constituiu um dos pilares centrais do projeto anarquista (Corrêa, 2010; ver também Coelho, 2014; Malon, 2014; Samis, 2011).

Mas por que a proposta federalista do anarquismo "fracassa diante da necessidade de direcionamento e organização das sociedades modernas"? Ela é precisamente uma forma organizativa cuja direção é dada pela "base". Por que fracassaria nessa tarefa? Há algum caso em que o direcionamento social deva se dar pelo "cume"? Existem boas justificativas para pensarmos que o "cume" estaria mais bem legitimado a fazê-lo do que a "base"? E se o "cume" não está mais bem legitimado, por que fracassaria o projeto anarquista?

A meu ver, o que fundamenta essa objeção de Habermas é uma interpretação do projeto anarquista enquanto modelo utópico em contraposição a um modelo de crítica imanente. Essa é a objeção que Habermas (1993; ver também Ferry 2003) faz à Hannah Arendt ([1958] 2010), cuja análise do poder se daria em âmbito normativo - tendo o modelo grego como referência - mas não verdadeiramente crítico $^{11}$. Por isso, pode nos ser útil apresentar as objeções de Habermas à Arendt e, posteriormente, avaliar se elas se transferem ao projeto anarquista.

\section{Objeções de Habermas à Arendt}

Segundo Habermas, Hannah Arendt compreende a esfera política como o âmbito da ação comunicativa e da razão prática (praxis em sentido aristotélico) que lhe é própria. Esse modo de compreender o político tem por consequência - e é

11 Esse tipo de objeção pressupõe (i) uma clara distinção entre discurso "utópico" e discurso "crítico" e (ii) a superioridade do segundo sobre o primeiro. Mesmo que o programa de pesquisa da Teoria Crítica dependa desses pressupostos, eles são substanciais. Enquanto o primeiro pressuposto distingue irredutivelmente, por exemplo, abordagens analíticas de abordagens críticas, o segundo afirma a superioridade da segunda sobre a primeira. No entanto, é preciso levar em conta que essas teses são amplamente disputadas. Contra (i), poder-se-ia supor uma abordagem analítico-crítica (tal como a de Hugh Lacey em suas análises sobre a ciência). Contra (ii), poder-se-ia defender um pluralismo de abordagens ou até mesmo a superioridade da abordagem analítica. 
da intenção de Arendt - a eliminação da ação estratégica e da razão instrumental ou técnica (technè) de seu escopo.

Habermas busca evitar tal compreensão. Primeiro, porque mesmo que essa noção pudesse ser tomada como um ideal e, portanto, tivesse valor normativo, a esfera política assim concebida possuiria baixa fecundidade como categoria descritiva e, portanto, seria pouco útil para interpretações empíricas. Desse modo, segundo Habermas, ao fazer tal delimitação, Arendt tem o ônus de:

a) excluir da esfera política todos os elementos estratégicos, definindo-os como violência; b) isolar a política dos contextos econômicos e sociais em que está embutida através do sistema administrativo; c) não poder compreender as manifestações da violência estrutural. (Habermas, 1993, p. 111).

Nesse nível, a objeção de Habermas à Arendt é de teor empírico. Poderia, por exemplo, ser realizada por um funcionalista ou um teórico dos sistemas. Mas Habermas não pretende se comprometer com a posição estritamente objetivista dos teóricos dos sistemas, na medida em que ela é conservadora e, portanto, não crítica. Dessa forma, ele busca uma alternativa entre a posição de Arendt, que considera "idealista", e a posição "realista" (ou resignante) dos teóricos dos sistemas ${ }^{12}$. Trata-se de uma alternativa entre (1) um conceito de política rico de sentido, mas sem um correspondente na realidade empírica (Arendt, supostamente) e (2) um conceito bem ajustado à realidade atual, mas sem qualquer sentido emancipatório (teóricos dos sistemas). No primeiro caso, como já comentado, faltaria adequação empírica para a interpretação do processo político. No segundo caso, o conceito de política é reduzido à pura technè, perdendo toda a dimensão intersubjetiva da razão prática.

A objeção de Habermas à Arendt - e ao pensamento "idealista" em geral, expresso em (1) - possui também um teor

12 Assim colocado, o idealismo e o objetivismo são duas abordagens a que o modelo crítico busca se afastar. Enquanto à primeira falta empiria, na segunda os fenômenos empíricos são analisados sem qualquer perspectiva emancipatória. O modelo crítico, em contrapartida, visa uma abordagem interdisciplinar que congrega normatividade e descrição, de modo que os potenciais emancipatórios possam ser identificados no real. (Contudo, ver nota 6). 
crítico-normativo, além de empírico. Como um representante da abordagem conhecida como Teoria Crítica, Habermas entende que os potenciais emancipatórios precisam ser buscados enquanto inscritos no real. Não é apenas empiricamente inviável, mas normativamente inviável a abordagem que não busque na realidade um lugar privilegiado à manifestação da práxis.

Tanto Habermas quanto Arendt (e também os anarquistas) visualizam os potenciais emancipatórios no entendimento comunicativo - que é característico do mundo da vida - e não na linguagem própria do sistema. No entanto, conforme aponta Habermas, o poder em Arendt é, de modo exclusivo, um poder comunicativamente produzido. Por ser fundamentado numa teoria da ação de inspiração aristotélica, refere-se exclusivamente à práxis (a fala recíproca e a ação conjunta dos indivíduos, como fim em si mesmo). Embora essa conceituação nos permita uma crítica da situação contemporânea como altamente burocratizada, tecnicamente centrada e essencialmente afastada dos conteúdos práticos do processo político, Habermas identificou, como vimos na citação acima, o ônus que ela possui.

Para evitar tal ônus, Habermas procura estender o conceito de poder, de modo a incluir a ação estratégica, além da ação comunicativa. De acordo com o autor, para Arendt, a ação estratégica é essencialmente apolítica, na medida em que busca a efetivação de meios para atingir um fim. Habermas, pelo contrário, mesmo mantendo a distinção entre ação comunicativa e ação estratégica, não elimina a última de seu conceito de poder. Para ele, a gestação do poder necessita, de fato, ser explicada pela práxis do entendimento comunicativo. Contudo, tanto a aquisição quanto o exercício do poder não podem ser explicados por essa categoria. Precisamos, segundo ele, da ação estratégica para tal.

O conceito do político deve estender-se para abranger também a competição estratégica em torno do poder político [aquisição do poder] e a aplicação do poder ao sistema político [exercício do poder]. A política não pode ser idêntica, como supõe H. Arendt, à práxis daqueles que conversam entre si, a fim de agirem em comum [gestação do poder]. Inversamente, a teoria dominante [sistêmica] restringe esse conceito aos fenômenos da concorrência em torno do poder e da alocação do poder, sem fazer justiça ao fenômeno específico da gestação do poder. (Habermas, 1993, p. 115) 


\section{As objeções de Habermas à Arendt se transferem ao projeto anarquista?}

E quanto ao projeto anarquista? Estaria ele inevitavelmente preso aos mesmos problemas que Habermas atribui à Arendt ${ }^{13}$. Para responder tal pergunta, precisamos descobrir se (1) esse projeto pode ser concebido como "idealista", isto é, se ele não busca os potenciais emancipatórios inscritos no real, e se (2) ele não concebe um espaço (tanto descritivo quanto normativo) para a ação estratégica em sua compreensão da esfera pública. Se essas duas suposições mostrarem-se corretas, então o projeto anarquista sofre as mesmas objeções que a abordagem de Arendt. Se formos capazes de mostrar que (1) e (2) são falsas, então as objeções de Habermas à Arendt não se transferem ao projeto anarquista. Mais do que isso, a tese do fracasso de tal projeto será desmotivada.

Certamente, todo projeto militante visa incidência na realidade. Por isso, precisa avaliar os meios para atingir e aprofundar essa incidência. Em outros termos, necessita de ação estratégica (contrariamente à suposição 2). Para que essa ação se efetive, os meios - pelo menos aqueles que permitem dar início à estratégia - precisam estar disponíveis e ser identificados. Em outros termos, precisam ser buscados enquanto inscritos no real (contrariamente à suposição 1). Dessa forma, tanto o "idealismo" quanto a eliminação da ação estratégica no âmbito público são luxos a que nenhuma organização militante poderia se dar.

Para manter a ligação com o início do texto, citarei novamente Bakunin e Malatesta, dois dos principais teóricos clássicos do anarquismo. Primeiro, vejamos o que Bakunin tem a nos dizer:

Um programa político só tem valor quando, saindo das generalidades vagas, determina bem precisamente as instituições que propõe para o lugar daquelas que deseja derrubar ou reformar. (Bakunin, 2016 [1876], p. 255)

13 Não estou assumindo a adequação das objeções de Habermas à Arendt. Fiz uma breve apresentação de suas objeções com o interesse único em investigar se elas podem se transferir ao projeto anarquista. Uma avaliação das objeções de Habermas à Arendt exigiria outro trabalho, com foco diferente. 
Bakunin entende, no entanto, que esse programa político não pode ser imposto burocraticamente aos membros da organização. É por isso que ele se contrapôs, naquele momento, a um programa político oficial para a Associação Internacional dos Trabalhadores (A.I.T.). Isso não significa que ele era contra a politização da A.I.T., tal como muitos interpretam. De fato, essa interpretação não se sustenta, na medida em que Bakunin pertencia, à época, à Aliança da Democracia Socialista, uma organização anarquista com programa político definido e que atuava no interior da A.I.T. Em vez de ser contra a politização, suas críticas eram endereçadas à tentativa de se impor, burocraticamente, um programa político único e obrigatório a todas as seções da A.I.T.

Resumindo: ao introduzir a questão política no programa obrigatório da Internacional, colocou-se nossa Associação em um terrível dilema, do qual eis os dois termos:

Ou a unidade com a escravidão,

Ou a liberdade com a divisão e a dissolução.

Como sair disso? Simplesmente retornando a nossos estatutos gerais primitivos, que fazem abstração da questão propriamente política, deixando seu desenvolvimento para a liberdade das federações e das seções. (Bakunin, 2016b [1872], p. 250, grifos do autor)

De modo a não produzir "escravidão", por um lado, nem dissolução, por outro, Bakunin se coloca contra um programa político obrigatório para a A.I.T. ${ }^{14}$. Essa posição não decorre de uma falta de visão estratégica por parte de Bakunin. Pelo contrário, ele identifica o dilema e propõe uma saída. Trata-se precisamente de uma visão estratégica que busca os meios para atingir um fim. Seu raciocínio é moldado pela interação entre princípios (normativos) e circunstâncias (empíricas). Com efeito, não há nada de idealista nesse raciocínio.

Podemos ter uma interpretação similar a respeito de Malatesta:

(...) não basta desejar uma coisa: se se quer obtê-la, é preciso, sem dúvida, empregar os meios adaptados à sua realização. E esses meios não são arbitrários: derivam necessariamente dos fins a que

14 A seu ver, o programa político dessa associação deveria ser consequência de uma construção estabelecida "de baixo para cima", não de uma imposição estabelecida burocraticamente a todas suas seções. 
nos propomos e das circunstâncias nas quais lutamos. Enganandonos na escolha dos meios, não alcançamos o objetivo contemplado, mas, ao contrário, afastamo-nos dele rumo a realidades frequentemente opostas, e que são a consequência natural e necessária dos métodos que empregamos. Quem se põe a caminho e se engana de estrada, não vai aonde quer, mas aonde o conduz o caminho tomado. (Malatesta, 1989b [1903], p. 21)

Malatesta está enfatizando a importância da identificação e avaliação dos meios para se aproximar do fim proposto. Trata-se, em outros termos, da busca pelos potenciais emancipatórios inscritos no real. Essa visão lhe permite afirmar que "não se trata [...] de chegar à anarquia hoje, amanhã ou em dez séculos, mas caminhar rumo à anarquia hoje, amanhã e sempre" (Malatesta, 1989c [1910], p. 64). Diferente do que alguns podem supor, esse pensamento não enfraquece a perspectiva revolucionária do anarquismo. Pelo contrário, fortalece-a. Sem a avaliação dos meios e a atuação efetiva, não se pode conscientemente transformar a realidade. Sem visualizar as atuais potencialidades e desenvolvê-las, o fim permanecerá sempre distante. Nesse sentido, Malatesta entende que a revolução precisa ser construída. Ela não virá de um suposto determinismo histórico, nem de um espontaneísmo anti-organizacional, nem da mera combinação entre condições econômicas e políticas próprias do sistema. Ela exige visão estratégica e atuação efetiva no mundo da vida. Requer um acúmulo de forças e um enraizamento consciente nas camadas populares.

Essa concepção move Malatesta - e grande parte dos anarquistas organizados - a defender a coerência entre meios e fins, o que se poderia conseguir apenas a partir de ações prefigurativas. Por isso a identificação dos potenciais emancipatórios é crucial, e ela deve ser buscada nos ambientes que possam prefigurar, mesmo que em gérmen, a sociedade futura.

Voltemos agora à objeção de Habermas. Pode-se justificadamente afirmar que o projeto anarquista sofre os mesmos problemas que Habermas atribui à Arendt? Sofre ele de um idealismo e de uma falta de visão estratégica? Certamente o anarquismo não é um bloco homogêneo, com sua história de mais de 150 anos e sua presença nos cinco continentes. No 
entanto, Bakunin e Malatesta estão entre os principais clássicos anarquistas, reivindicados por boa parte das organizações. Se a objeção de Habermas não se adequa a dois dos principais teóricos do anarquismo, a quem ela deveria se adequar?

Mais que uma falta de adequação aos principais teóricos anarquistas, essa objeção de Habermas não se ajusta às práticas anarquistas historicamente efetivadas. Por exemplo, não se ajusta (i) às já mencionadas revoluções exitosas em que o anarquismo foi protagonista, como no México, Ucrânia, Manchúria e Espanha, (ii) aos diversos movimentos com tendências anarquistas ou libertárias, desde o sindicalismo revolucionário e o anarco-sindicalismo em muitos países, até o maio de 1968 francês, os cordões industriais no Chile entre 1972 e 1973, os movimentos "anti-globalização", o neozapatismo, etc. e (iii) à ação das próprias organizações anarquistas.

(i), (ii) e (iii) foram meros idealismos sem visão estratégica? Ou será que o idealismo está, não no projeto anarquista, mas na interpretação de Habermas? Como muito bem destacaram, há mais de 90 anos, os autores da Plataforma: "o anarquismo não é uma bela fantasia retirada da imaginação de um filósofo, mas um movimento social das massas trabalhadoras" (Dielo Truda, 2017 [1926], p. 8). Tudo indica que essa crítica de Habermas ao projeto anarquista é desmotivada.

Até agora, apresentei evidências com base em teóricos clássicos do anarquismo e em momentos históricos com protagonismo, participação ou influência anarquista. No próximo tópico, analisarei uma vertente atual do anarquismo organizado, que despontará como mais uma evidência contra a objeção de Habermas. O objetivo, contudo, será mais geral: analisar a concepção de poder nessa vertente do anarquismo.

\section{Anarquismo e poder nos dias de hoje: um estudo de caso com a Coordenação Anarquista Brasileira (CAB)}

Todo projeto político constrói seu discurso com alguma noção de poder. A noção pressuposta (ou explicitamente defendida) acaba sempre por adquirir um duplo papel: teórico, de 
descrição ou interpretação de fenômenos, por um lado; e normativo, de valoração negativa ou positiva desses fenômenos, por outro. A um projeto político, espera-se que sua noção de poder sirva razoavelmente bem a esses dois fins, e o quão bem ela servirá é certamente contexto-dependente.

Pode-se ter uma concepção completamente crítica do poder (caso dos clássicos anarquistas, que identificavam poder com dominação), uma concepção completamente positiva (caso de Arendt, que, segundo Habermas, identificava poder com práxis, em sentido aristotélico) ou, ainda, uma concepção matizada, que pode ou não ser crítica a depender de como o poder se expressa (caso de Habermas e, como veremos, também da $\mathrm{CAB}$ ). Pretendo abordar brevemente esse tema a partir de uma vertente atual do anarquismo organizado no Brasil.

Trata-se da Coordenação Anarquista Brasileira (CAB), composta por onze federações estaduais que compartilham um programa e uma estratégia geral ${ }^{15}$. A primeira edição da revista Socialismo Libertário, editada pela CAB, intitula-se Nossa concepção de Poder Popular (CAB, 2012) ${ }^{16}$. O texto inicia com a seguinte passagem, de autoria da Federación Anarquista Uruguaya (FAU):

$15 \quad$ A CAB se situa numa vertente do anarquismo denominada "especifismo" ou "anarquismo especifista". Tal vertente foi inicialmente formulada pela Federación Anarquista Uruguaya (FAU) nas décadas de 1950 e 1960. Ela possui similaridades com o "plataformismo", vertente formulada na Europa nos anos 1920. No entanto, a estratégia especifista foi formulada pelos uruguaios independentemente, sem que tenham tido contato com o plataformismo.

16 O tema do poder popular pode ser encontrado em outras publicações da CAB (como em <https://anarquismo.noblogs.org/files/2015/06/ soli-28.pdf> e < https://anarquismo.noblogs.org/files/2015/06/soli-30-11. pdf $>$ ), além das publicações próprias das federações que a compõem. Para fins de exemplo, pode ser encontrado no Programa da FARJ-RJ intitulado Anarquismo social e Organização (disponível em < http://www.farj.org/>), no material da OASL-SP intitulado Anarquismo Especifista e Poder Popular (disponível em <https://anarquismosp.files.wordpress.com/2013/11/poderpopular-impressao.pdf $>$ ) e no texto de Apresentação da FAG-RS (disponível em < https://federacaoanarquistagaucha.wordpress.com/sobre/>). Os links foram acessados em 06 de outubro de 2018. 
Uma concepção e uma prática de autogestão têm, em sua produção específica, seu próprio discurso. Têm sua própria produção de poder que, nesse caso, é de poder popular. (FAU apud CAB, 2012, p. 8)

É interessante notar como esse trecho aproxima a noção de poder à noção de discurso. Parece que ter "seu próprio discurso", enquanto produto de uma concepção e uma prática autogerida, implica ter "sua própria produção de poder". E, se o poder é assim produzido, então ele é de um tipo específico, o chamado poder popular. Em linhas gerais, é análogo ao poder comunicativamente produzido (de Arendt), porque é resultado do entendimento e da ação comunicativos. Porém, na medida em que é qualificado como poder popular, supõe-se (diferente do conceito de Arendt) que não esgote o sentido da categoria de poder.

Após duas páginas, a CAB apresenta sua concepção de poder:

Concebemos o poder como uma relação social estabelecida a partir do enfrentamento entre diversas forças sociais, quando uma ou mais forças se impõem às outras. (CAB, 2012, p. 10).

Enquanto, no primeiro trecho, da FAU, o poder é compreendido enquanto agir comunicativo com fim em si mesmo (chamemo-lo poder-1), esse último trecho aborda o poder enquanto enfrentamento e imposição de uma ou mais forças sociais sobre outras, com vistas à realização de algum fim (chamemo-lo poder-2).

Dessa forma, podemos estabelecer as seguintes analogias. O poder-1 é o conceito de poder em Arendt, é o agir comunicativo em Habermas e é o poder popular para a FAU (e para a $\mathrm{CAB}$ e suas organizações, como veremos). O poder-2 é um poder que envolve ação estratégica. Para Arendt, significa que é violência e não poder. Para Habermas, pode ser poder ou violência, a depender do tipo de imposição. Para a CAB (e também para a FAU), trata-se sempre de poder. Sua análise não contrapõe poder à violência. Enquanto o poder pode ser efetivamente não violento, a violência é vista sempre como uma manifestação do poder. Inclusive a dominação é entendida pela $\mathrm{CAB} / \mathrm{FAU}$ enquanto poder, porque não se trata da violência es- 
trutural depurada dos elementos que lhe dão suporte, mas de todo o aparato que gere e oculta essa violência através de um manto de legitimação. Portanto, a CAB/FAU compreende o que denominamos poder-1 e poder-2 enquanto formas de poder. É esperado, portanto, que essas formas de poder tenham papel descritivo e normativo. Vejamos.

Numa sociedade em que, descritivamente, o agir comunicativo (poder-1) é profundamente limitado pela imposição coercitiva (poder-2) - seja pela colonização do mundo da vida pelo sistema, seja pelas relações de dominação no interior do próprio mundo da vida - é necessário, normativamente, contrapor tal imposição (poder-2) se queremos ampliar a esfera pública igualitária requerida para o agir comunicativo (poder-1). Em outros termos, é necessário impor o poder popular como forma de resistência a um poder dominador.

Numa sociedade de classes, em que uns mandam e outros obedecem, a concentração de poder é estrutural e, portanto, as condições para a ação comunicativa são apenas marginais. Se desejamos ampliar as possibilidades do agir comunicativo, estamos visando um fim e, portanto, devemos pensar nos meios ou na instrumentalização capazes de nos aproximar de tal fim. Isso significa que, para alcançarmos uma sociedade baseada no agir comunicativo (ou no poder popular, estou tomando-os como forma de expressão do poder-1) precisamos conceber os meios para impor esse ideal. Em outros termos, para que o poder-1 deixe de ser marginal e passe a ser estruturante, precisamos levar em conta o poder-2.

De fato, o poder popular (poder-1) é entendido pela $\mathrm{CAB}$ como o resultado de um projeto de longo prazo ${ }^{17}$. Surge, então, a pergunta sobre como agir de modo a fortalecer a cons-

$17 \quad$ É interessante notar que o poder popular é entendido como resultado de um projeto. Nesse sentido, deve resultar da relação entre meios e fins; deve resultar de ação estratégica, portanto. Dessa forma, a CAB/FAU entende que o poder popular, que é um agir comunicativo com fim em si mesmo, depende da ação estratégica para se concretizar. De fato, atuar na construção do poder popular implica agir estrategicamente com a finalidade de possibilitar a ampla manifestação do agir comunicativo. Portanto, a CAB/FAU dá um papel imprescindível à ação estratégica. 
trução do poder popular. Para responder tal pergunta, a Organização Anarquista Socialismo Libertário (OASL-SP), membro da CAB, em seu material Anarquismo Especifista e Poder Popular apresenta trechos de entrevista com Juan Carlos Mechoso, militante fundador da FAU, dos quais cito a seguinte parte:

O poder popular se fortalece na medida em que os movimentos sociais utilizam a democracia direta como método decisório, ao tomarem decisões de maneira igualitária e coletiva, fortalecendo a construção pela base, ou seja, "de baixo para cima" ou "da periferia para o centro", e acabando com as relações de dominação que existem dentro deles. Neste sentido, a construção do poder popular envolve um processo de democratização dos organismos de base, um exercício de democracia solidária, de participação direta e de construção da consciência de classe, que só tem sentido a partir de uma associação voluntária. Processo que se fortalece pelo exercício permanente da autogestão e do federalismo, em organismos amplamente democráticos e participativos, apropriando-se da política que privilegia a esfera do Estado.

O fortalecimento do poder popular se dá a partir de iniciativas que têm por objetivo dar protagonismo aos movimentos sociais, atuando pela ação direta - e, portanto, fora das instâncias da democracia representativa - e com autonomia em relação a instrumentos, instituições e/ou indivíduos, sendo capaz de autodeterminação e de auto-sustentação. (OASL, 2011, p. 14-15)

Em linhas gerais, podemos dizer que a CAB/FAU entende o poder como um espectro que vai da dominação (caso em que o poder-2 é fortemente concentrado) até a autogestão, democracia direta ou poder popular (poder-1, distribuído igualitariamente). Essa concepção pode ser observada no seguinte trecho:

Em oposição à dominação e ao modelo de poder que a caracteriza, o poder dominador, defendemos a autogestão e o federalismo libertário, caracterizados por um modelo de poder autogestionário e federalista, chamado por nós de poder popular. A autogestão e o federalismo são o oposto da dominação e implicam a participação no planejamento e nos processos decisórios, proporcionalmente ao quanto se é afetado por eles, pessoal, grupal ou coletivamente. Sua aplicação generalizada implica a substituição de um sistema de dominação por uma sociedade igualitária/libertária. (CAB, 2012, p. 11)

Ao criticar a dominação e defender a autogestão, a CAB está ciente de que propõe uma nova forma de poder. De fato, na medida em que não é contra o poder, mas contra as formas 
dominantes em que o poder opera, ela pode defender, sem contradição, o que chama de poder popular e, inclusive, disputar tal conceito. A Federação Anarquista do Rio de Janeiro (FARJ), membro da $\mathrm{CAB}$, assim destaca:

Se por poder popular entendemos a crescente força social das organizações das classes exploradas, que estão inseridas em uma disputa permanente com o capitalismo e com o Estado, então estamos de acordo [com a concepção de outros grupos]. No entanto, há aqueles que defendem o poder popular como a sustentação de vanguardas descoladas da base, hierarquia, partidos autoritários, reivindicações do Estado e burocracias de vários tipos. Quando poder popular significa este segundo modelo, então estamos em completo desacordo. (FARJ, 2009, p. 52)

Apesar de haver amplo consenso sobre esse tema no interior da $\mathrm{CAB}$ desde seu nascimento em 2012 e no interior da FAU há mais de meio século, o debate sobre o poder e sobre o poder popular continua vivo entre os anarquistas. Esse debate foi tema do livro Anarquismo y Poder Popular: Teoría y Práctica Suramericana (VVAA, 2011) e se estendeu em outras publicações, como os artigos do brasileiro Felipe Corrêa (2014) e do venezuelano Rafael Uzcátegui (2014), com posições divergentes, na revista Ekintza Zuzena.

\section{Considerações finais}

Pretendi oferecer uma breve análise do conceito de poder nos anarquistas, trazendo para o debate Habermas e sua crítica ao conceito de poder em Arendt. Vimos que o poder nos clássicos anarquistas é identificado com a dominação. Precisamos ter isso em mente quando lemos que esses anarquistas eram contra o poder. Defender atualmente uma forma de poder não implica entrar em contradição com os clássicos anarquistas, desde que o conceito de poder seja mobilizado com outro sentido. Se anarquistas defendem o poder popular - isto é, se são de fato anarquistas e defendem uma forma de poder -, então esse poder deve ser incompatível com a dominação. A defesa do poder popular (em seu sentido libertário) implica a defesa de uma forma de poder completamente oposta ao poder dominador. Poder popular e poder dominador são extremos 
opostos de um espectro de poder. Com base nessa concepção, não seria possível (nem desejável) defender uma forma de organização social em que o poder esteja ausente. O poder popular traz consigo uma característica essencialmente positiva, na medida em que ele é condição para a ação genuína.

Vimos que os anarquistas clássicos concebiam a dominação enquanto exercida por classes dominantes, em especial pela burguesia e pela burocracia. A crítica à dominação e às classes dominantes continua como uma crítica estrutural entre os anarquistas, com a inclusão principalmente da crítica ao patriarcado e ao colonialismo.

Quanto a Habermas e sua objeção à noção de poder arendtiana, eles foram importantes para colocar os termos do debate e permitir um aprofundamento na análise. Busquei mostrar que aquelas críticas de Habermas endereçadas ao anarquismo carecem de justificação, e que a perspectiva anarquista tem pontos em comum tanto com Arendt quanto com Habermas, devido à ampla valorização do agir comunicativo e por não excluir o papel da ação estratégica.

\section{Agradecimentos}

Agradeço à CAPES pela bolsa de doutorado e ao Rafael Viana da Silva, estudioso do anarquismo, e ao Felipe Gonçalves Silva, estudioso de Habermas e da Teoria Crítica, pelas contribuições dadas a este texto.

\section{Referências}

ARENDT, Hannah. A Condição Humana. 11ed. Revisão de Adriano Correia. Rio de Janeiro: Forense Universitária, 2010.

ARSHINOV, Piotr. História do Movimento Macknovista: a insurreição dos camponeses na Ucrânia. Lisboa: Assírio e Alvim, 1976.

BAKUNIN, Mikhail. A ilusão do sufrágio universal. In: WOODCOCK, George. (Org.). Os Grandes Escritos Anarquistas. Porto Alegre: LP\&M, 1998. 
BAKUNIN, Mikhail. Relações pessoais com Marx. In: COELHO, Plínio Augusto. (Org.). Bakunin: Obras Seletas 1. São Paulo: Intermezzo, 2016a.

BAKUNIN, Mikhail. Escritos contra Marx. In: COELHO, Plínio Augusto. (Org.). Bakunin: Obras Seletas 1. São Paulo: Intermezzo, $2016 \mathrm{~b}$.

BERTHIER, René. Do Federalismo. São Paulo: Editora Imaginário, 2011.

CAB. Nossa Concepção de Poder Popular. Socialismo Libertário, n.1, 2012. Disponivel em: <https://anarquismo.noblogs.org/files/2015/06/Revista-Soli-01-2012-web.pdf > . Acesso em: 06 out. 2018.

COELHO, Plínio Augusto. (Org.). A Comuna de Paris: Considerações Libertárias. São Paulo: Intermezzo/Imaginário, 2014.

CORRÊA, Felipe. (Introdução). Política, Classe e Transição: o debate clássico entre as estratégias do anarquismo e do marxismo. In:

BERTHIER, René. Poder, Classe Operária e "Ditadura do Proletariado". São Paulo: Imaginário/Faísca, 2010.

CORREAA, Felipe. Poder y Anarquismo: ¿ Aproximación o Contradicción? Ekintza Zuzena, n. 41, 2014. Disponível na metade inicial desta página: < https://www.nodo50.org/ekintza/spip.php?article614>. Acesso em: 06 out. 2018.

CRISI, Emilio. Revolución anarquista em Manchuria 1929-1932. Ciudad Autónoma de Buenos Aires: Libro de Anarres, 2015.

DIELO TRUDA. A Plataforma Organizacional da União Geral dos Anarquistas (Projeto). Trad. InaHergert. Instituto de Teoria e História Anarquista: ITHA, 2017. Disponível em: < https://ithanarquista. files.wordpress.com/2017/01/dielo-truda-a-plataforma-organizacional-nova-traduc3a7c3a3o.pdf $>$. Aceso em: 06 out. 2018.

DOLGOFF, Sam. The Relevance of Anarchism to Modern Society.

Minneapolis: Soil of Liberty, 1977. Disponível em: <https://theanarchistlibrary.org/library/sam-dolgoff-the-relevance-of-anarchism-tomodern-society.a4.pdf>. Acesso em: 06 out. 2018.

FARJ. Anarquismo Social e Organização. Rio de Janeiro: Federação Anarquista do Rio de Janeiro, 2009. Disponível em: < http://www. farj.org/>. Acesso em 06 out. 2018.

FERRY, Jean-Marc. Habermas: Crítico de Hannah Arendt. Trad. Silvia G. B. dos Santos em Educação e Filosofia, v.17, n.33, 2003.

GUÉRIN, Daniel. O Anarquismo: da doutrina à ação. Rio de Janeiro: Germinal, 1968.

HABERMAS, Jürgen. Soberania Popular como Procedimento: um conceito normativo de espaço público. Trad. Márcio Suzuki em Novos estudos, n. 26, 1990. 
HABERMAS, Jürgen. O conceito de poder de Hannah Arendt. In B. Freitag e S. P. Rouanet. Habermas: Sociologia. 3ed, 1993.

HABERMAS, Jürgen. Teoría de la Acción Comunicativa. (2 tomos). Madrid: Taurus, 2001.

HOBSBAWM, Eric. Revolucionários: ensaios contemporâneos. 2ed. Rio de Janeiro: Paz e Terra, 1985.

KROPOTKIN, Piotr. Modern Science and Anarchism. London: Freedom Press, 1912. Disponível em: < http://www.bibliotekacyfrowa. pl/Content/77403/Kropotkin_P_Modern_Science_and_Anarchism. pdf $>$. Acesso em: 06 out. $201 \overline{8}$.

LE LIBERTAIRE; LE MONDE LIBERTAIRE. (Org.). Espanha libertária: a revolução contra o fascismo. São Paulo: Imaginário, 2002.

LEVAL, Gaston; BERTHIER, René; MINTZ, Frank. Autogestão e Anarquismo. São Paulo: Imaginário, 2002.

MALATESTA, Errico. A Organização I. In: Escritos Revolucionários. São Paulo: Novos Tempos, 1989a.

MALATESTA, Errico. Programa Anarquista. In: Escritos Revolucionários. São Paulo: Novos Tempos, 1989 b.

MALATESTA, Errico. Rumo à Anarquia. In: Escritos Revolucionários. São Paulo: Novos Tempos, 1989c.

MALATESTA, Errico. El reformismo. In: RICHARDS, Vernon. (Org.). Malatesta: pensamiento y acción revolucionarios. Buenos Aires: Tupac Ediciones, 2007.

MALATESTA, Errico. Errico Malatesta: Anarquistas, Socialistas e Comunistas. São Paulo: Intermezzo/Imaginário, 2014.

MALON, Benoît. A Internacional: sua história e seus princípios. São Paulo: Imaginário, 2014.

OASL. Anarquismo Especifista e Poder Popular. São Paulo: Organização Anarquista Socialismo Libertário, 2011.

SAMIS, Alexandre. (Apresentação). In: MAGON, Ricardo Flores. A Revolução Mexicana. São Paulo: Imaginário, 2003.

SAMIS, Alexandre. Negras Tormentas: o Federalismo e o Internacionalismo na Comuna de Paris. São Paulo: Hedra, 2011.

SCHMIDT, Michael; VAN DER WALT, Lucien. Black Flame: the revolutionary class politics of anarchism and syndicalism. Oakland: AK Press, 2009.

SCHMIDT, Michael; VAN DER WALT, Lucien. Chapter 1: Introduction. In: Black Flame: the revolutionary class politics of anarchism and syndicalism. Oakland: AK Press, 2009. Há uma tradução para o português disponível em: <https://ithanarquista.files.wordpress. 
com/2013/08/michael-schmidt-e-lucien-van-der-walt-apresentandochama-negra.pdf $>$. Acesso em: 27 set. 2018.

SCHUJMAN, Héctor. La Revolución Desconocida: Ukrania 1917-1921, la gesta makhnovista. Mostoles: Nossa y Jara, 2000.

SHUBIN, Aleksandr. The Makhnovist Movement and the National Question in Ucraine, 1917-1921. In HIRSCH, Steven; VAN DER WALT, Lucien. (Org.). Anarchism and Syndicalism in the Colonial and Postcolonial World, 1870-1940. Leiden: Koninklijke NV, 2010.

SILVA, Rafael Viana da. Os Revolucionários Ineficazes de Hobsbawm: reflexões críticas de sua abordagem do anarquismo. São Paulo: Faísca Publicações Libertárias, 2015.

TREJO, Rubén. Magonismo: utopia y revolución, 1910-1913. Cidade do México: Cultura Libre, 2005.

UZCÁTEGUI, Rafael. El anarquismo estado céntrico del poder popular. Ekintza Zuzena, n.41, 2014. Disponível na metade final desta página: <https://www.nodo50.org/ekintza/spip.php?article614>. Acesso em: 06 out. 2018.

VVAA. Anarquismo y Poder Popular: teoría y práctica sur americana. Bogotá/Manresa: Gato Negro/Rojinegro, 2011.

ZARCONE, Pier Francesco. Os Anarquistas na Revolução Mexicana. São Paulo: Faísca, 2006. 